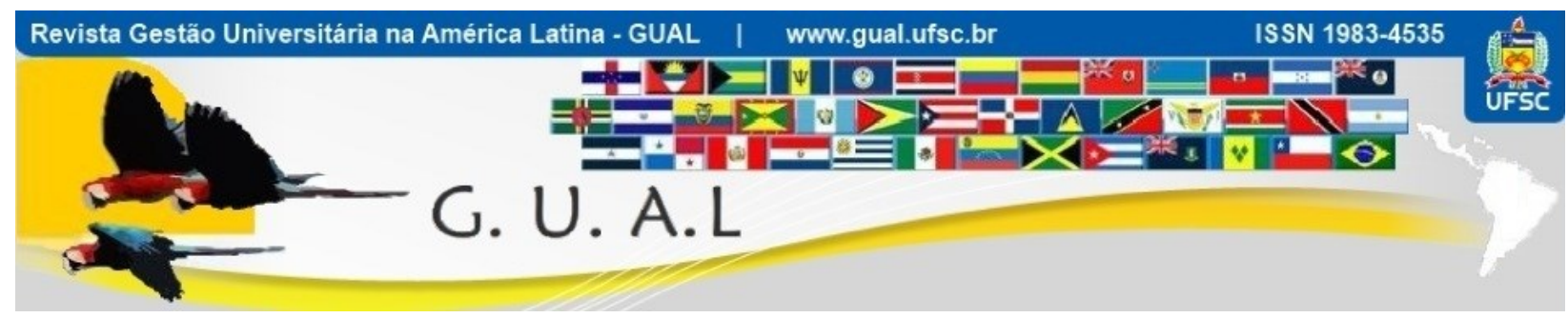

DOI: http://dx.doi.org/10.5007/1983-4535.2013v6n3p310

\title{
PANORAMA DA SATISFAÇÃO DOS ACADÊMICOS DA FACULDADE DE ESTUDOS SOCIAIS DA UNIVERSIDADE FEDERAL DO AMAZONAS
}

\section{OVERVIEW OF ACADEMIC'S SATISFACTION FROM THE FACULTY OF SOCIAL STUDIES AT THE FEDERAL UNIVERSITY OF AMAZONAS.}

Vanessa da Silva Miranda, Graduanda

Universidade Federal do Amazonas - UFAM vdsm03@hotmail.com

Valéria Epifânio da Silva, Graduanda Universidade Federal do Amazonas - UFAM valeriaepifaniosilva@gmail.com

Ygor Angelim do Carmo, Graduando Universidade Federal do Amazonas - UFAM ygor.angelin@gmail.com

Waldemar Antonio da Rocha de Souza, Doutor Universidade Federal do Amazonas - UFAM prof.wsouza@gmail.com

Luiza Maria Bessa Rebelo, Doutora Universidade Federal do Amazonas - UFAM 1mbrebelo@gmail.com

Recebido em 01/maio/2013

Aprovado em 17/julho/2013

Sistema de Avaliação: Double Blind Review 


\title{
RESUMO
}

O presente estudo teve como objetivo avaliar o grau de satisfação dos alunos da Faculdade de Estudos Sociais (FES) da Universidade Federal do Amazonas (UFAM) no que concerne às condições físico-pedagógicas oferecidas em seus cursos. A pesquisa foi realizada com base numa amostra de 310 universitários, sendo 48\% do curso de Administração, 26\% do curso de Ciências Contábeis e 26\% do curso de Ciências Econômicas. Para aferir os dados aplicou-se um questionário com 27 questões, a partir do qual foi possível observar que os atributos referentes aos conteúdos curriculares; instrumentos pedagógicos; mecanismos de avaliação de aprendizagem; relação entre professores e alunos; professores esclarecem dúvidas; e ética dos professores foram avaliados com elevados graus de aprovação, destacando-se como os pilares que sustentam a satisfação com o ensino na instituição pesquisada. No entanto, os acadêmicos demonstraram desaprovação em relação à estrutura física da faculdade, sobretudo, nos aspectos de instalações sanitárias; biblioteca; e salas de aula.

Palavras-chave: Pesquisas de Satisfação. Estrutura Físico-Pedagógica. Qualidade do Ensino.

\begin{abstract}
The aim of this present study was to evaluate the satisfaction rate of the students from the Social Studies Faculty (FES) from the Federal University of Amazonas (UFAM) when it comes to the physical - pedagogical conditions offered in their courses. The research was made based on a sample of 310 students, being $48 \%$ from Business, $26 \%$ from Accounting Sciences and 26\% from Economics Sciences. To assess the information a survey with 27 questions was carried out and from which it was possible to notice that the atributes concerning curricular contents, pedagogical instruments, assessment learning mechanisms, professors/students dynamic, doubt solving matters by professors and professor's ethics were evaluated with high rates of approval, being then pointed out as the fundamental aspects to which these ones are satisfied with the institution researched. However, students demonstrated desapproval in relation to university's physical structure, especially about toilets, library and classrooms.
\end{abstract}

Keywords: Satisfaction Surveys. Physical and Pedagogical Structure. Quality of Education. 


\section{INTRODUÇÃO}

A aplicação de pesquisas de satisfação é uma ferramenta importante para a formação de um ensino de qualidade, Demo (1998) destaca que a atividade de ensinar e aprender vai além do modismo de transmitir conceitos obsoletos, ou da mera atividade de repassar saber.

Cada vez mais as Instituições de Ensino Superior (IES) são cobradas pelo melhor desempenho, no intuito de maximizar a qualidade da formação do aluno, por conseguinte a elaboração de pesquisas tem um papel fundamental para traçar estratégias de melhorias nesse âmbito, visto a competição ferrenha no mercado de trabalho, a qual tem levado os estudantes a procurar estabelecimentos que realmente tenham um compromisso com o aprendizado. Ademais, a partir dos resultados obtidos com a realização de estudos deste gênero, formar-seá um arcabouço de oportunidades para melhoria da gestão acadêmica.

No entanto, a educação brasileira ainda não atentou completamente para a importância da otimização do ensino e de sua infraestrutura no desenvolvimento do país, visto a necessidade de capital humano devidamente capacitado para as demandas do mesmo. De acordo com Neves e Ramos (2001), no cenário atual, as instituições de ensino superior devem preocupar-se com a manutenção de elevados níveis de satisfação frente aos seus alunos, para tanto, não podem limitar-se a ser simples fornecedoras de conhecimento, necessitando estar atentas para uma contínua adaptação das suas estruturas às transformações ocorridas no ambiente. Desta forma, ambas as partes são beneficiadas, pois a instituição mantém-se competitiva e preserva sua imagem de excelência, por meio da oferta das melhores condições de formação profissional, enquanto os acadêmicos alcançam a almejada inserção no mercado de trabalho.

Haja vista o aumento do número de pessoas com nível superior no mercado, faz-se mister a criação de um diferencial para o aluno, porquanto as universidades com seu aparato pedagógico e infraestrutura exercem papel crucial nisso e ao utilizarem instrumentos de pesquisa, no intuito de munir-se com informações que possam ser utilizadas como base para futuras mudanças, cooperam com o processo de aperfeiçoamento da qualidade do ensino, investigando o que pensam seus alunos a respeito da referida instituição, quais são suas demandas, procurando conhecer realmente a visão de seus acadêmicos. Assim, o presente estudo trará como feedback a realidade supracitada, isto é, o fornecimento de informações que colaborem para a elaboração de projetos futuros no âmbito universitário. 
Conforme o exposto, apesar da comprovada relevância das pesquisas de satisfação, a existência de tais estudos na óptica dos alunos da Faculdade de Estudos Sociais (FES) ${ }^{1}$ mostrou-se nula, fato esse que motivou a realização do estudo. Desta forma, este artigo objetivou responder a seguinte questão de pesquisa: avaliar o grau de satisfação dos alunos da Faculdade de Estudos Sociais da Universidade Federal do Amazonas (UFAM) quanto às condições físico-pedagógicas oferecidas em seus cursos.

Dessa análise, especificamente, pretendeu-se:

i - identificar os motivos dos alunos para a escolha do curso e da universidade;

ii - analisar a opinião dos alunos em relação à infraestrutura geral da faculdade;

iii - examinar a opinião dos alunos com relação à qualidade do ensino, identificando a adequação do conteúdo curricular, práticas didáticas dos professores e correspondência entre as disciplinas e as demandas do mercado de trabalho.

\section{REVISÃO DE LITERATURA}

A correlação estabelecida entre infraestrutura, conteúdo curricular e qualidade de ensino é o elemento essencial para a formação de profissionais aptos a transpor as barreiras impostas pelo mercado de trabalho, tais como: o aumento da competitividade e o novo contexto mundial impostos com a inserção de novas tecnologias. As universidades são responsáveis por fornecerem as condições necessárias ao bom desenvolvimento deste processo e, por isso, precisam estar prontas para atenderem as demandas cada vez mais exigentes, oferecendo boa qualificação profissional com conteúdos e processos pedagógicos atualizados.

De acordo com Rolim et al. (2007), é evidente que os alunos detêm responsabilidade sobre a qualidade de sua formação e sobre o desenvolvimento das aptidões exigidas para a prática profissional, no entanto, as Instituições de Ensino Superior compartilham das mesmas responsabilidades, devendo primar pelo seu cumprimento.

Martins (1985) afirma que o conhecimento somente se torna significativo quando vinculado à realidade dos alunos, focando na promoção de instrumentos para a resolução dos problemas práticos. De posse disso, é importante que as universidades públicas e privadas ofereçam serviços de ensino superior de qualidade, dinamizando as formas pedagógicas e

\footnotetext{
${ }^{1}$ Sigla destinada à divisão que abrange os cursos de Administração, Ciências Contábeis e Ciências Econômicas da Universidade Federal do Amazonas (UFAM).
} 
relacionando-as com o meio, considerando fatores como qualidade do ensino e infraestrutura, determinantes no processo de aprendizagem por influenciarem diretamente na satisfação do aluno.

UFAM (2011a) ressalta que, no âmbito das universidades, qualidade de ensino não é apenas um modismo do discurso administrativo, mas o compromisso social, econômico, político, cultural e ético na formação de indivíduos críticos e capazes de contribuir efetivamente para a consolidação e o desenvolvimento da sociedade. Segundo Dencker (2002), as universidades devem formar indivíduos para integrá-los ao mercado de trabalho, sintonizando-os com o sistema produtivo. De tal modo que permita uma formação adequada, beneficiando tanto o profissional, quanto a organização em que atua, bem como o sistema econômico e social em que se insere.

As universidades devem manter-se permanentemente atualizadas com estrutura adequada e professores capacitados para a contínua produção de conhecimentos. Para Berger (1999), o constante processo de aprendizagem resulta em profissionais habilitados para atuarem no mercado e no desenvolvimento de uma sociedade, na qual o dinamismo e a reinvenção tornem-se características intrínsecas a sua cultura.

De acordo com Vanderley e Kottwitz (2011), o mercado de trabalho exerce uma pressão cada vez maior sobre o perfil profissional desejado, no sentido de fomentar novos métodos para a execução do trabalho, seja por meio da operação de novas máquinas ou pelo desenvolvimento de novas habilidades. Por sua vez, Ansarah (1996, p.16), destaca que: "Do ponto de vista macro, os cursos devem dar aos estudantes uma ampla visão multidisciplinar com interfaces, possibilitando a interdisciplinaridade". Diante do exposto, assegura-se que o aluno, ao encerrar os estudos, encontre-se preparado para exercer atividades profissionais que requeiram dinamismo e conhecimentos múltiplos.

Segundo Walter, Tontini e Domingues (2005), para que uma IES melhore os cursos e serviços oferecidos é importante identificar as necessidades sociais atuais e futuras, levando em consideração as mudanças ocorridas e avaliando permanentemente currículos, disciplinas e formas de ensino, com o intuito de transformar o processo de melhoria contínua em parte da cultura organizacional.

A exemplo do que ocorre em outras instituições de ensino superior, a Universidade Federal do Amazonas necessita atingir metas de melhoria da qualidade do ensino com a utilização de mecanismos que efetuem uma avaliação institucional, por conseguinte, a 
realização de tal avaliação deve ser entendida como um processo contínuo de crescimento, que objetiva contribuir para o aperfeiçoamento da prática pedagógica e para o aumento permanente da eficácia institucional e da efetividade acadêmica e social da UFAM.

De posse disso, foram consultados outros estudos similares feitos em IES de regiões distintas do país, como é o caso da pesquisa aplicada por Vieira, Milach e Huppes (2008) junto aos alunos do curso de Ciências Contábeis da Universidade Federal de Santa Maria (UFSM), na qual o objeto de pesquisa foi a avaliação dos determinantes da satisfação geral desses estudantes com relação a seu curso. Nota-se no referido estudo que a satisfação dos alunos é influenciada positivamente por elementos como: o interesse do estudante pelo curso realizado e pelo desempenho dos docentes, no que tange, por exemplo, ao compromisso com o aprendizado dos acadêmicos e a capacidade de relacionar as teorias expostas com a prática profissional. Tal constatação serviu de base para a realização da pesquisa na UFAM, a qual considerou a opinião dos alunos no universo da IES, tornando-os agentes avaliadores do trabalho realizado pelos professores, bem como conduzindo-os a uma reflexão acerca de suas aspirações ao escolherem o respectivo curso, além de seus objetivos e necessidades no meio acadêmico.

Outro estudo semelhante foi a pesquisa aplicada por Campos, Martins e Lopes Neto (2011) em uma IES privada no Rio Grande do Norte, onde a qualidade do serviço prestado pela universidade foi analisada com base nas expectativas e percepções do serviço recebido pelos alunos de Administração e Ciências Contábeis. Os resultados indicam um déficit de qualidade nos 31 atributos pesquisados, no entanto, os fatores de descontentamento são diferenciados para cada um dos cursos. Em Administração, as maiores lacunas observadas advém do serviço de segurança interna e da quantidade/diversidade do acervo bibliográfico, já no curso de Ciências Contábeis, as principais críticas referem-se aos serviços e informações disponíveis no site, ao atendimento da direção do curso e à pontualidade dos professores.

Ainda nessa temática, a pesquisa realizada por Rowe (2004) na Universidade Presidente Antônio Carlos - UNIPAC, uma IES privada em Visconde do Rio Branco, Minas Gerais, teve como escopo a percepção dos acadêmicos do curso de Administração com relação à metodologia de ensino adotada pelos docentes e às habilidades necessárias ao administrador. O estudo foi realizado entre os meses de outubro e novembro de 2001 e, entre os resultados apontados, destacam-se aqueles relacionados às expectativas dos alunos para a melhoria do curso, especialmente, a necessidade de qualificação para o aperfeiçoamento da 
metodologia de ensino superior desenvolvida pelos professores, no intuito de dinamizar as aulas e facilitar o processo de aprendizagem.

Ademais, os acadêmicos também apontaram necessidades de melhorias na infraestrutura da universidade, tais como: reforma do prédio para tornar as salas de aula mais arejadas, ampliação do acervo da biblioteca, seguida da implementação de uma área reservada para estudos e disponibilização de mais computadores no laboratório de informática.

O trabalho de Rowe (2004) também contribui para a reafirmação da importância de pesquisas deste gênero, tendo em vista que, no próprio texto, o autor afirma que em 2002, a biblioteca do campus recebeu novos livros em seu acervo e o laboratório de informática passou por um processo de modernização. Tais acontecimentos evidenciam um esforço da UNIPAC no sentido de reconhecer as demandas de seus alunos e satisfazê-las, o que se faz necessário não somente para a melhoria do processo de ensino-aprendizagem, mas também para a manutenção da competitividade da instituição, por se tratar de uma universidade particular

Conforme o exposto no exemplo supracitado, a partir da realização de pesquisas de satisfação, estabelece-se um fluxo de informações entre a administração superior e as unidades acadêmicas, que constituirá subsídios extremamente relevantes para o aperfeiçoamento do processo de ensino-aprendizagem e da cultura avaliativa e administrativa da Instituição pesquisada. Os resultados da avaliação também podem ser usados para a gestão administrativa das unidades acadêmicas, como suporte na elaboração de ajuste curricular, na implementação de novos projetos pedagógicos, na melhoria das condições da estrutura física, no planejamento orçamentário e na elaboração de planos de trabalho capazes de corrigir as dificuldades detectadas no processo de avaliação (UFAM, 2011b).

Contudo, UFAM (2011b) propõe que, essa cultura só poderá materializar-se com a adesão e a conscientização por parte de toda a comunidade universitária de que a avaliação é um processo contínuo e sistemático que exclui ações de ameaça ou punição, pois seus resultados objetivam proporcionar mudanças e correções dos problemas que prejudicam o desempenho dos docentes, dos alunos, dos técnicos administrativos e da IES em si.

\section{METODOLOGIA}

Para o alcance do objetivo deste estudo, optou-se pela realização de pesquisa exploratória-descritiva (VERGARA, 2009). Exploratória, pela ausência de outros estudos na 
Faculdade de Estudos Sociais da UFAM que abordassem o grau de satisfação dos estudantes em relação às condições físico-pedagógicas oferecidas em seus cursos. E descritiva, porque objetivava identificar percepções, expectativas e sugestões dos alunos da FES em relação à estrutura física e à qualidade de ensino da faculdade.

Ademais, os métodos foram classificados como pesquisa documental, bibliográfica e de campo (VERGARA, 2009). Pesquisa Documental, pois foram consultados dados secundários disponíveis no Manual de Avaliação de Reconhecimento dos Cursos de Graduação do MEC, como auxílio na elaboração do questionário, bem como em documentos internos da Divisão de Matrícula da Pró-Reitoria de Ensino de Graduação (PROEG), a respeito da quantidade de alunos matriculados nos turnos matutino e vespertino nos cursos de Administração, Ciências Contábeis e Ciências Econômicas cujos valores, respectivamente, foram 508, 276 e 280, que juntos compõem um universo de 1064 acadêmicos (UFAM, 2011c). Pesquisa Bibliográfica, pois para a fundamentação teórico-metodológica do trabalho realizou-se investigação sobre a satisfação dos alunos de instituições de ensino superior. E de Campo, pois aplicou-se um questionário no local de estudo dos acadêmicos da Faculdade de Estudos Sociais, na Universidade Federal do Amazonas.

O cálculo amostral tomou por base UFAM (2011d) que, a partir da população geral de 1.064 alunos, estimou uma proporção de $0,5 \%$, com margem de erro fixada em 0,05 ou 5\%, com grau de confiança de 95\%, obtendo uma amostra de 282 indivíduos, aos quais foram acrescidos $10 \%$ de perda, valor médio considerado em trabalhos desta natureza devido a possíveis erros no preenchimento do questionário. Desta forma, chegou-se a um número estimado de 310 alunos a serem entrevistados, dentre os quais $48 \%$ deveriam pertencer ao curso de Administração, 26\% ao curso de Ciências Contábeis e 26\% ao curso de Ciências Econômicas.

De acordo com Vergara (2009), a amostra da pesquisa classificou-se em probabilística aleatória simples, pois realizaram-se sorteios das salas ocupadas pelos cursos da FES, permitindo chances iguais de participação a todas as turmas entre o $1^{\circ}$ e o $7^{\circ}$ períodos. Dentre os alunos que responderam aos questionários 51\% referem-se ao sexo masculino e $49 \%$ ao sexo feminino, com média de idade de 26 anos.

Para a coleta dos dados aplicou-se um questionário composto por 27 perguntas, divididas em: uma pergunta dicotômica, uma aberta, três fechadas e 22 questões de acordo com a escala de Lickert, que varia de 1 a 5, para indicar o grau de discordância ou 
concordância do entrevistado em relação a determinadas afirmações. Para as questões embasadas na escala de Lickert, foram utilizadas as váriaveis contidas no Quadro 1. Tais variáveis formaram duas grandes divisões, agrupando-se por características humanas (V1V11) e físicas (V12-V21).

\begin{tabular}{|c|c|}
\hline Código & Nome da Variável \\
\hline V1 & Procedimentos Didáticos dos Professores \\
\hline $\mathrm{V} 2$ & Professores relacionam teoria e prática \\
\hline V3 & Conteúdos curriculares \\
\hline V4 & Promoção de Atividades de Ensino, Pesquisa e Extensão \\
\hline V5 & Instrumentos Pedagógicos \\
\hline V6 & Instrumentos Adotados para Desencadear a Aprendizagem \\
\hline V7 & Mecanismos de Avaliação de Aprendizagem \\
\hline V8 & Relação entre Professores e Alunos \\
\hline V9 & Professores esclarecem Dúvidas \\
\hline V10 & Ética dos Professores \\
\hline V11 & Assiduidade dos Professores \\
\hline V12 & Estrutura Física favorece o Processo de Ensino-Aprendizagem \\
\hline V13 & Auditórios \\
\hline V14 & Instalações Sanitárias \\
\hline V15 & Biblioteca \\
\hline V16 & Estacionamento \\
\hline V17 & Iluminação \\
\hline V18 & Laboratório de Informática \\
\hline V19 & Rampas para Pessoas com Deficiência \\
\hline V20 & Salas de Aula \\
\hline V21 & Quantidade de Alunos por Turma \\
\hline
\end{tabular}

Quadro 1 Variáveis correspondentes as assertivas do questionário Fonte: Pesquisa de Campo (2011).

A seguir, realizou-se um pré-teste do questionário com cinco pessoas, que não detinham vínculo com o público alvo da pesquisa, no intuito de aferir a adequação e a compreensão do instrumento. A partir desta aplicação, o questionário foi aprovado, estando apropriado à pesquisa. Desta forma, pôde-se dar início a coleta de dados, a qual foi realizada no período de 08 à 10 de junho de 2011.

Os dados primários coletados foram tabulados e são apresentados na tabela de distribuição por frequência com média e desvio-padrão de cada variável analisada. Para completar o estudo, realizou-se a Análise Fatorial (AF) que objetiva identificar as dimensões de variabilidade comum existentes num conjunto de variáveis, distinguindo as estruturas 
existentes que não são diretamente observáveis. Definem-se as dimensões como fatores (CORRAR; PAULO; DIAS FILHO, 2012).

A modalidade de AF mais aplicada é a Análise Fatorial Exploratória (AFE), que não exige conhecimento prévio da relação de dependência das variáveis. Os resultados da AFE apontaram a estrutura de relacionamento, coerente ou não, entre as variáveis.

Assim, usou-se a AFE neste estudo para identificar a relação entre as variáveis mais representativas do grau de satisfação dos alunos da FES da UFAM a partir das variáveis apontadas nas questões. Examinaram-se as seguintes relações a partir dos resultados dos questionários aplicando a escala de Likert: pesos fatorias, para identificar as variáveis mais representativas, e o gráfico bidimensional entre os fatores.

Ademais, justifica-se o uso da análise fatorial exploratória a partir dos resultados de pesquisas similares, tais como as realizadas por Siqueira e Carvalho (2006) e Camargos, Camargos e Machado (2006). Enquanto Siqueira e Carvalho (2006) utilizaram a AF para depuração e análise de dimensionalidade para validação da escala de pesquisa realizada com acadêmicos de Administração de uma instituição pública e outra privada do Rio de Janeiro, no intuito de investigar as diferenças na percepção de qualidade e na satisfação dos alunos. Camargos, Camargos e Machado (2006), por sua vez, aplicaram essa técnica estatística multivariada na avaliação das respostas fornecidas pelos estudantes de Administração de uma universidade particular de Belo Horizonte acerca das condições de ensino oferecidas.

Os softwares utilizados para a tabulação dos dados foram, respectivamente, o Microsoft Office Excel, versão 2007, para a organização inicial dos dados, e o Statistics Data Analysis (Stata) versão 8.0, para efetuar os testes da análise fatorial.

\section{ANÁLISE E DISCUSSÃO DOS DADOS}

Essa seção aborda os resultados da pesquisa de forma a responder as indagações contidas no escopo do estudo. Para tanto, será apresentada com base em gráficos e tabelas. Tendo em vista que, o papel das IES é preparar profissionais qualificados, estas devem estar suscetíveis às exigências e demandas do mercado, sobretudo, às preferências dos alunos quanto à qualidade de ensino e às condições do que está sendo oferecido. Deste pressuposto surge a importância de identificar o perfil dos estudantes, assim, os dois primeiros gráficos serão representativos ao perfil dos alunos dos cursos da FES. 
Entre os alunos entrevistados nos cursos de Administração, Ciências Contábeis e Ciências Econômicas, pôde-se observar uma leve propensão para o gênero masculino, com diferença de apenas $2 \%$ com relação à população feminina da FES, visto que $51 \%$ dos acadêmicos são do sexo masculino e $49 \%$ do sexo feminino.

O primeiro gráfico destaca os motivos que levaram os estudantes a escolherem seus cursos.

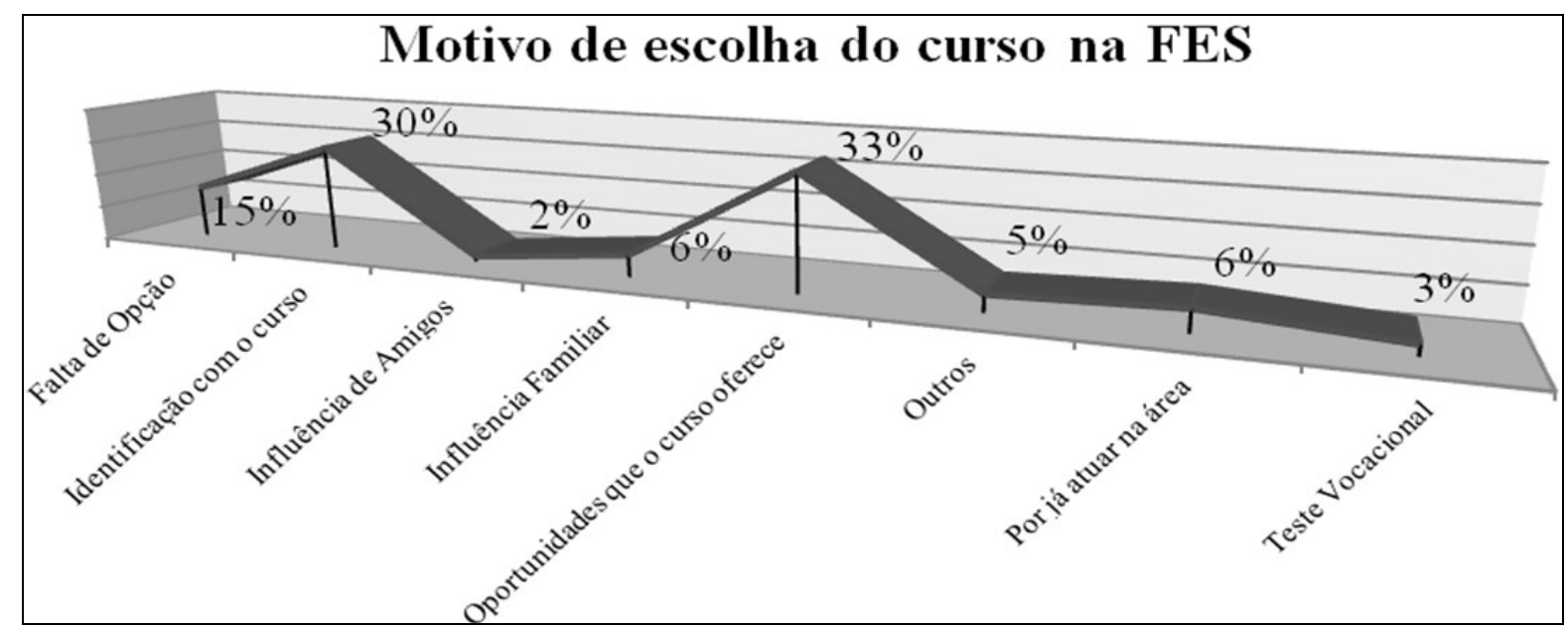

Gráfico 1 Motivo de escolha do curso na FES

Fonte: Pesquisa de campo (2011).

Verificaram-se variações nos motivos de escolha do curso citados pelos alunos da Faculdade de Estudos Sociais, entre as razões mais mencionadas pelos estudantes, pôde-se destacar: oportunidades que o curso oferece com um percentual de 33\% de menção; identificação com o curso $30 \%$; e falta de opção com 15\%.

De acordo com o estudo de Vieira, Milach e Huppes (2008), o interesse manifestado pelo aluno em relação ao conteúdo estudado no curso constitui um indicador relevante para a satisfação dos acadêmicos com o curso e para a determinação do perfil e do desempenho do futuro profissional. Com base no exposto e considerando a realidade da FES, $30 \%$ dos estudantes revelaram que se identificam com seus respectivos cursos, portanto, os mesmos tenderão a tornarem-se profissionais bem sucedidos, pois estarão atuando na área que apreciam.

No entanto, o Gráfico 1 revelou uma realidade preocupante, pois concentrou percentuais referentes aos mais diversos motivos para a escolha do curso de graduação, como: oportunidades que o curso oferece (33\%); falta de opção (15\%); influência familiar $(6 \%)$ e influência de amigos (2\%), os quais totalizaram $56 \%$ quando adicionados. Tais indicadores 
representaram uma espécie de incerteza dos alunos com relação à escolha de seu futuro profissional e, por conseguinte, estas dúvidas poderão resultar em uma série de problemas, como: aumento do índice de desistências dos cursos; possibilidade de futuras frustrações profissionais; diminuição da qualificação dos profissionais formados, o que acaba por degradar o nome da instituição de ensino e comprometer os níveis de serviços que deveriam ser oferecidos à sociedade por estes profissionais.

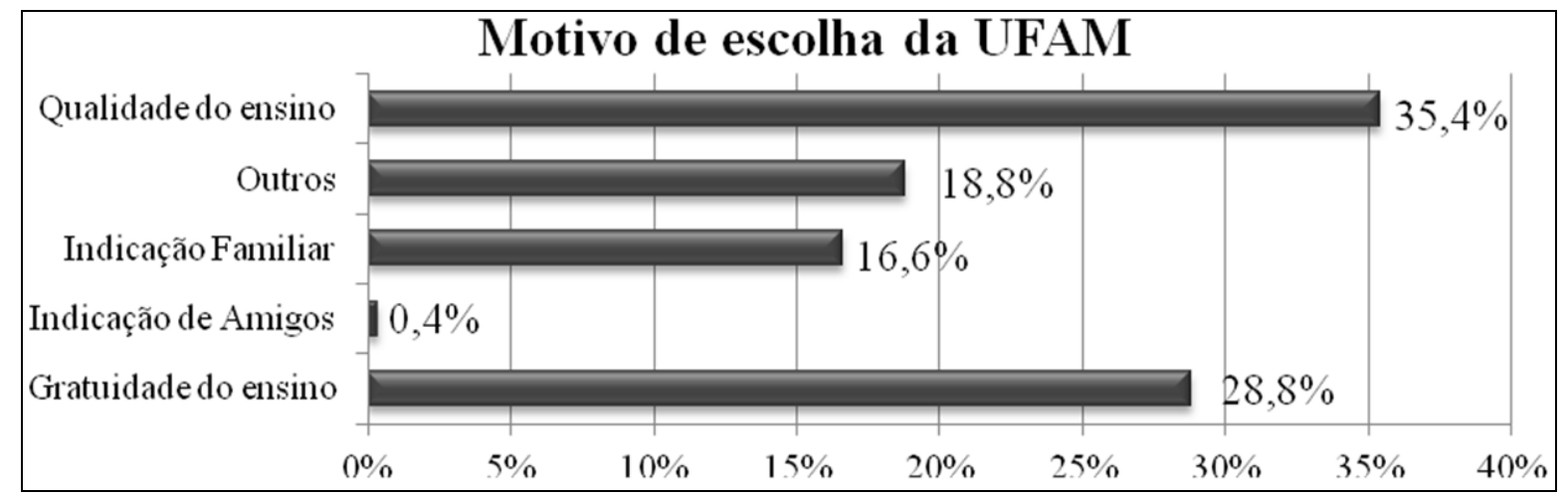

Gráfico 2 Motivo de escolha da UFAM

Fonte: Pesquisa de campo (2011).

Em relação aos motivos que levaram os estudantes a escolherem a Universidade Federal do Amazonas como instituição de ensino, se sobressaem: qualidade do ensino com $35,4 \%$ e a gratuidade do ensino com percentual de $28,8 \%$.

Tabela 1 Estatísticas descritivas dos fatores.

\begin{tabular}{|ccc}
\hline Código & Média & DP \\
\hline V1 & 3,24 & 0,80 \\
V2 & 3,20 & 1,00 \\
V3 & 3,44 & 1,07 \\
V4 & 2,79 & 1,01 \\
V5 & 3,46 & 1,08 \\
V6 & 3,06 & 0,95 \\
V7 & 3,66 & 1,06 \\
V8 & 3,51 & 0,98 \\
\hline V9 & 3,58 & 1,03 \\
V10 & 3,51 & 0,93 \\
V11 & 2,70 & 1,13 \\
V12 & 2,55 & 0,98 \\
V13 & 2,49 & 1,00 \\
V14 & 1,51 & 0,77 \\
V15 & 2,12 & 0,99 \\
V16 & 1,62 & 0,90 \\
V17 & 2,08 & 1,04 \\
V18 & 2,13 & 1,10 \\
\hline
\end{tabular}




\begin{tabular}{ccc} 
V19 & 2,64 & 1,34 \\
V20 & 2,46 & 1,05 \\
V21 & 2,29 & 1,23 \\
\hline
\end{tabular}

Fonte: Elaborado pelos Autores.

$\mathrm{Na}$ tabela acima registraram-se as estatísticas descritivas dos fatores, média e desviopadrão. Os pontos que mais se sobressaíram nas variáveis humanas (V1-V11) foram: conteúdos curriculares (V3) com média de 3,44; instrumentos pedagógicos (V5) com 3,46 de média; mecanismos de avaliação de aprendizagem (V7) com 3,66; relação entre professores e alunos (V8) com 3,51; e professores esclarecem dúvidas (V9) com 3,58. Entre as variáveis físicas, destacaram-se: estrutura física favorece o processo de ensino-aprendizagem (V12) com média de 2,55; auditórios (V13) com 2,49; rampas para pessoas com deficiência (V19) com 2,64; salas de aula (V20) com 2,46; quantidade de alunos por turma (V21) com 2,29.

Tabela 2 Pesos fatoriais, por ordem decrescente

\begin{tabular}{ccc}
\hline Código & Média & DP \\
\hline V12 & 0,43 & 0,07 \\
\hline V1 & 0,42 & 0,52 \\
V15 & 0,42 & 0,14 \\
V6 & 0,40 & 0,50 \\
V7 & 0,39 & 0,48 \\
V10 & 0,38 & 0,51 \\
V3 & 0,37 & 0,43 \\
V17 & 0,37 & 0,03 \\
V2 & 0,36 & 0,55 \\
V9 & 0,35 & 0,49 \\
V13 & 0,35 & 0,01 \\
V5 & 0,34 & 0,50 \\
V4 & 0,33 & 0,50 \\
V8 & 0,32 & 0,50 \\
V18 & 0,32 & 0,04 \\
V20 & 0,32 & $-0,13$ \\
V16 & 0,31 & 0,02 \\
V14 & 0,30 & $-0,11$ \\
V11 & 0,28 & 0,34 \\
V19 & 0,24 & 0,07 \\
V21 & 0,20 & $-0,09$ \\
\hline
\end{tabular}

Fonte: Elaborado pelos Autores.

$\mathrm{Na}$ tabela 2, observou-se os pesos fatoriais por ordem decrescente, dentre os quais destacaram-se o fator 0,43 correspondente a variável estrutura física favorece o processo de ensino-aprendizagem (V12) do grupo com características físicas, e o fator 0,42 referente a variável procedimentos didáticos dos professores (V1) do grupo com características humanas. 


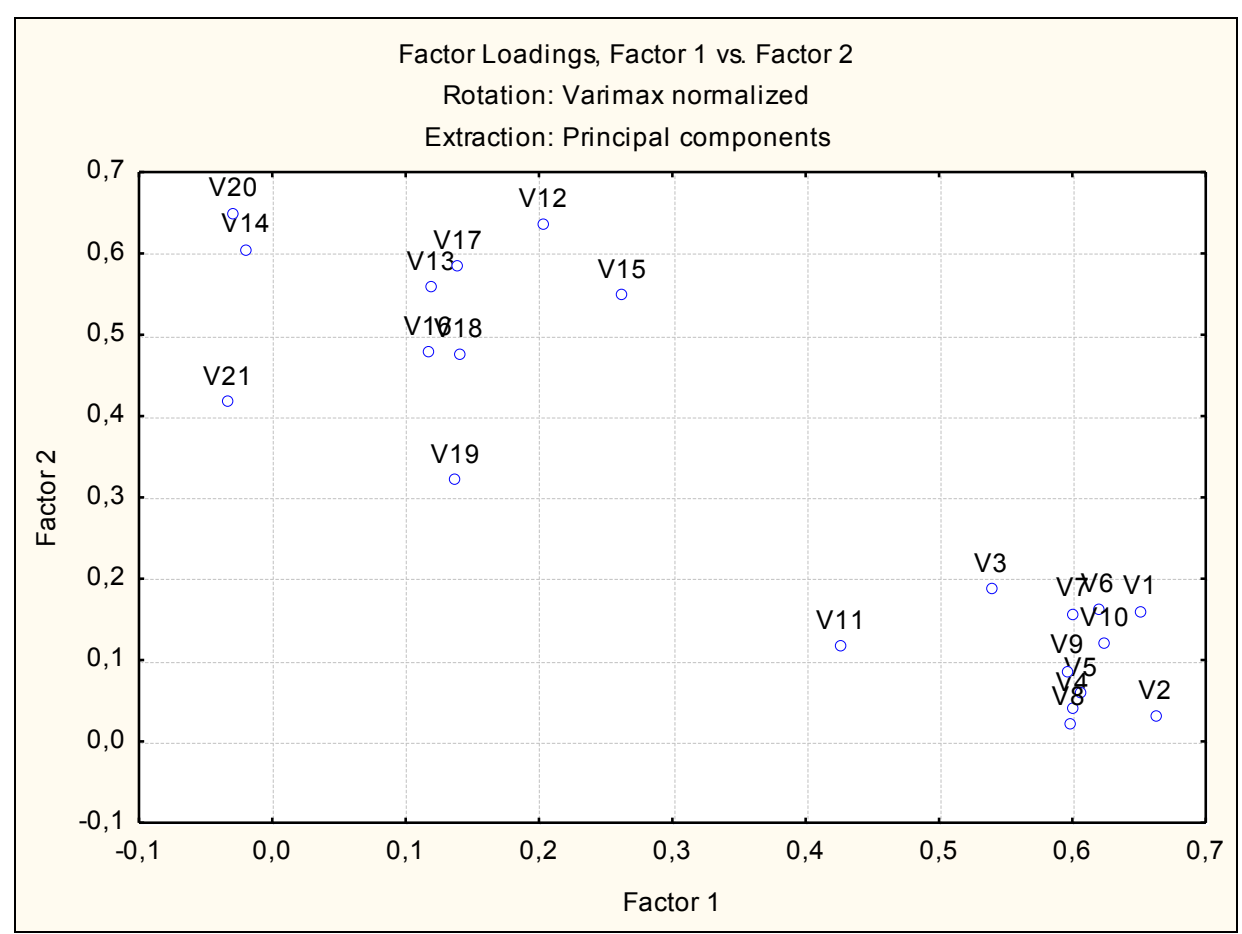

Gráfico 3 Cargas dos fatores com normalização de variância maximizada. Fonte: Pesquisa de campo (2011).

Ao observar o gráfico acima, percebeu-se o grupamento de dois grupos distintos, as variáveis V1-V11 no segmento inferior e as V12-V21 no segmento superior do Gráfico 3. O comportamento alinhou-se com a segmentação feita no questionário, dividido em duas partes, distinguindo variáveis humanas (V1-V11) e físicas (V12-V21).

Em suma, a Análise Fatorial Exploratória identificou as variáveis V1, V6 e V7 do grupo de características humanas e, V12, V15 e V17 do grupo de características físicas, como as mais importantes para avaliar o grau de satisfação dos alunos da FES da UFAM. Destacase que a técnica de análise fatorial exploratória auxiliou no estudo, evidenciando as variáveischaves que influenciaram na satisfação dos alunos, por apresentarem maior frequência. Entretanto, os gráficos abaixo foram analisados de forma holística, abordando o conjunto de atributos utilizados para avaliar as condições físicas e de ensino na FES. 


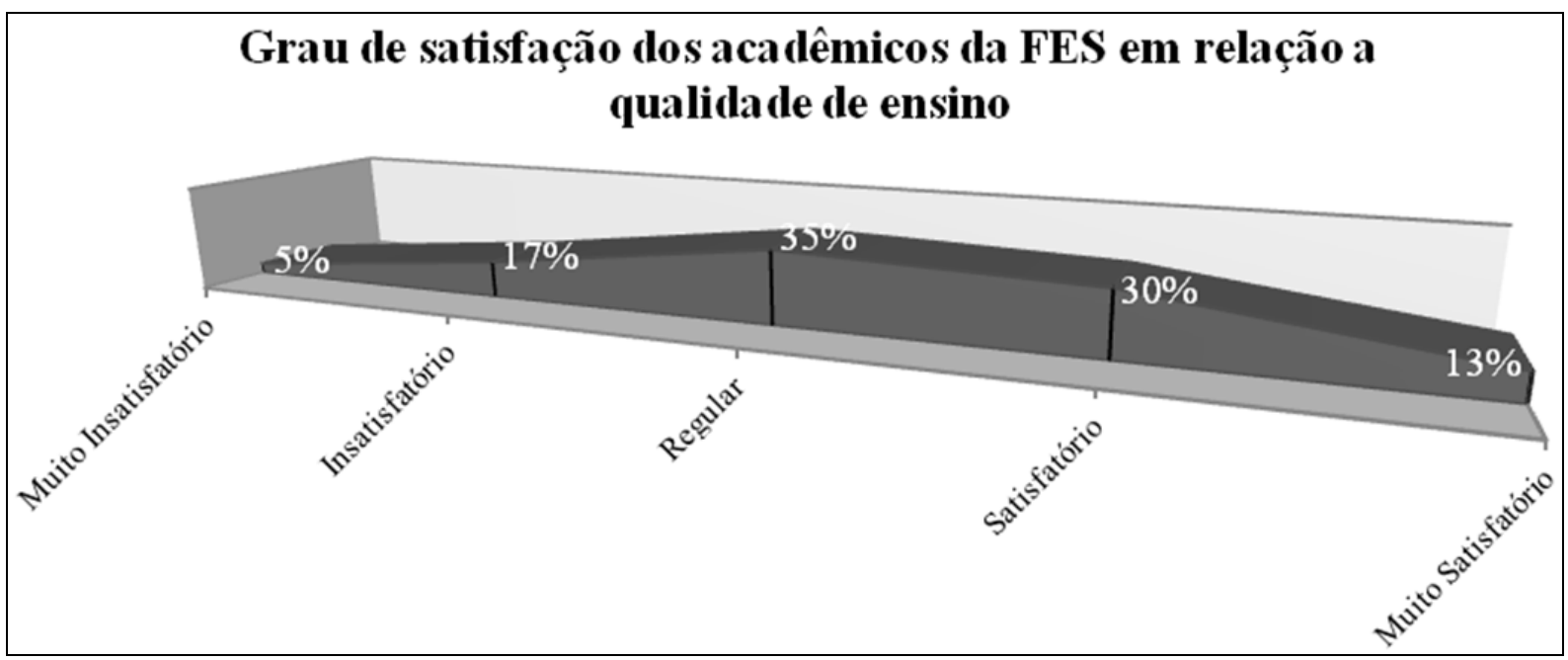

Gráfico 4 Grau de satisfação dos acadêmicos da FES em relação a qualidade de ensino Fonte: Pesquisa de campo (2011).

Ao observar o gráfico acima, verificou-se uma forte tendência para a aprovação da qualidade do ensino na FES por parte dos universitários, não obstante, 35\% dos estudantes ouvidos avaliarem o ensino como regular, como o próprio nome denota, esta categoria representa uma espécie de ponto médio em relação ao atributo avaliado, isto significa que, para estes acadêmicos, a qualidade do ensino na FES não está nem superior e nem inferior às suas expectativas. Assim, restam ainda quatro níveis de avaliação com os seguintes percentuais, respectivamente: muito satisfatório com 30\%; insatisfatório com 17\%; muito satisfatório com $13 \%$ e, por fim, muito insatisfatório com $5 \%$ da opinião dos inquiridos.

Ao somarem-se os percentuais dos níveis que tendem a aprovação da qualidade do ensino (satisfatório e muito satisfatório), obteve-se um percentual de 43\%, em contrapartida, os índices de desaprovação (insatisfatório e muito insatisfatório) totalizaram apenas $22 \%$, logo, os dados revelaram uma propensão para a aprovação da qualidade do ensino na FES. Ademais, reforça-se esta assertiva, por meio do exposto no Gráfico 2, o qual revelou que o principal fator motivador para o ingresso dos acadêmicos na instituição foi, exatamente, a qualidade do ensino oferecido, com um percentual de 35,4\% de menção.

$\mathrm{Na}$ Tabela 3 foram demonstrados os critérios utilizados para aferir a opinião dos alunos com relação à qualidade de ensino na FES e, consequentemente, obter-se os resultados expressos no Gráfico 4. 
Tabela 3 Atributos formadores do conceito de qualidade do ensino

\begin{tabular}{|c|c|c|c|c|c|}
\hline & $\begin{array}{c}\text { Muito } \\
\text { Insatisfatório }\end{array}$ & Insatisfatório & Regular & Satisfatório & $\begin{array}{c}\text { Muito } \\
\text { Satisfatório }\end{array}$ \\
\hline $\begin{array}{l}\text { Procedimentos } \\
\text { Didáticos dos } \\
\text { Professores }\end{array}$ & $3 \%$ & $10 \%$ & $55 \%$ & $27 \%$ & $6 \%$ \\
\hline $\begin{array}{c}\text { Professores } \\
\text { Relacionam teoria e } \\
\text { prática }\end{array}$ & $3 \%$ & $22 \%$ & $37 \%$ & $28 \%$ & $10 \%$ \\
\hline $\begin{array}{l}\text { Conteúdos } \\
\text { curriculares }\end{array}$ & $4 \%$ & $15 \%$ & $30 \%$ & $34 \%$ & $17 \%$ \\
\hline $\begin{array}{c}\text { Promoção de } \\
\text { Atividades de Ensino, } \\
\text { Pesquisa e Extensão }\end{array}$ & $10 \%$ & $28 \%$ & $39 \%$ & $17 \%$ & $5 \%$ \\
\hline $\begin{array}{l}\text { Instrumentos } \\
\text { Pedagógicos }\end{array}$ & $4 \%$ & $15 \%$ & $31 \%$ & $31 \%$ & $19 \%$ \\
\hline $\begin{array}{l}\text { Instrumentos } \\
\text { Adotados para } \\
\text { Desencadear a } \\
\text { Aprendizagem }\end{array}$ & $4 \%$ & $23 \%$ & $42 \%$ & $24 \%$ & $6 \%$ \\
\hline $\begin{array}{l}\text { Mecanismos de } \\
\text { Avaliação de } \\
\text { Aprendizagem }\end{array}$ & $2 \%$ & $14 \%$ & $23 \%$ & $37 \%$ & $24 \%$ \\
\hline $\begin{array}{c}\text { Relação entre } \\
\text { Professores e Alunos }\end{array}$ & $2 \%$ & $15 \%$ & $27 \%$ & $42 \%$ & $14 \%$ \\
\hline $\begin{array}{c}\text { Professores } \\
\text { Esclarecem Dúvidas }\end{array}$ & $2 \%$ & $13 \%$ & $30 \%$ & $34 \%$ & $21 \%$ \\
\hline Ética dos Professores & $2 \%$ & $11 \%$ & $36 \%$ & $38 \%$ & $14 \%$ \\
\hline $\begin{array}{l}\text { Assiduidade dos } \\
\text { Professores }\end{array}$ & $17 \%$ & $26 \%$ & $30 \%$ & $21 \%$ & $5 \%$ \\
\hline
\end{tabular}

Fonte: Pesquisa de Campo (2011).

Analisando a Tabela 3, percebeu-se que os atributos referentes aos conteúdos curriculares; instrumentos pedagógicos (ferramentas para estimular o interesse pelas aulas, como: vídeos, slides, apostilas, entre outros); mecanismos de avaliação de aprendizagem (diz respeito à diversidade dos mecanismos utilizados pelos docentes para a verificação da aprendizagem, tais como: provas escritas, seminários, estudos de casos e etc); relação entre professores e alunos; professores esclarecem dúvidas e, ética dos professores, foram avaliados com elevados graus de aprovação, destacando-se como os pilares que sustentam a qualidade do ensino na instituição pesquisada.

Ademais, os procedimentos didáticos dos professores (referem-se à clareza, objetividade e domínio do conteúdo, por parte dos docentes) e instrumentos adotados para desencadear a aprendizagem (como: estudos de caso, debates, simulações e etc) também foram avaliados positivamente pelos estudantes, embora não representem contribuições 
significativas para a satisfação destes com o ensino, pois apresentaram elevada incidência do nível de avaliação regular (55\% para procedimentos didáticos dos professores e $42 \%$ para os instrumentos adotados para desencadear a aprendizagem) se comparados à soma dos indicadores que tendem a aprovação, níveis satisfatório e muito satisfatório, os quais totalizaram, respectivamente, $33 \%$ e $30 \%$ quando adicionados.

Outra variável que tendeu a uma avaliação positiva foi a de professores relacionam teoria e prática, a qual recebeu um total de $38 \%$ de contentamento em detrimento de $25 \%$ de descontentamento. Contudo, esse fator não representou um atributo determinante para a qualidade geral do ensino por conta de uma elevada concentração de avaliação regular ao seu respeito - com menção de $37 \%$.

$\mathrm{O}$ item relativo à assiduidade dos docentes registrou maior indício de descontentamento por parte dos acadêmicos, mais especificamente $43 \%$, contra $26 \%$ de contentamento. Logo, para a maximização da qualidade do ensino nos cursos de graduação ofertados pela FES, faz-se mister que a direção da faculdade desenvolva um trabalho focado neste aspecto deficitário.

Destaca-se ainda a avaliação dos alunos quanto à promoção de atividades de ensino, pesquisa e extensão, pois apesar de 39\% dos estudantes manifestarem-se de forma indiferente, avaliando este atributo como regular, $38 \%$ dos acadêmicos consultados delinearam uma opinião negativa acerca desta variável. Desta forma, acredita-se que, após a assiduidade dos professores, o fator em questão represente uma potencial oportunidade de melhoria para a formação de uma imagem positiva do ensino na FES, bem como um diferencial para a instituição.

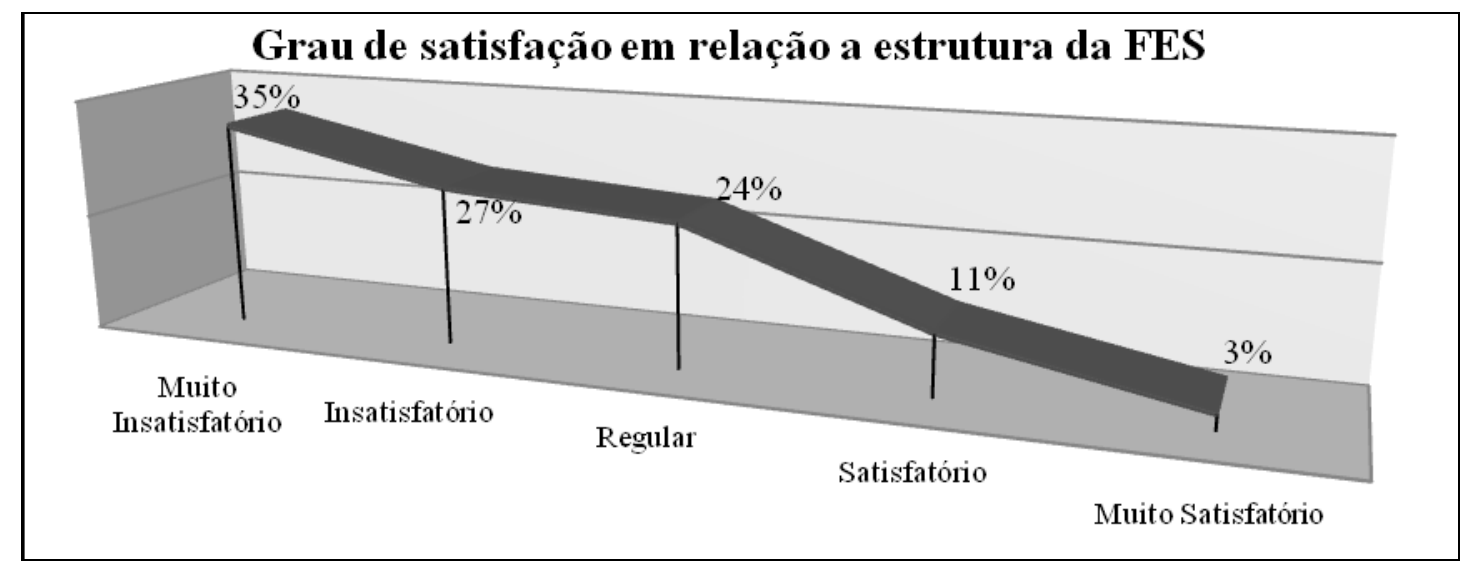

Gráfico 5 Grau de satisfação em relação a estrutura da FES

Fonte: Pesquisa de campo (2011). 
Observando o Gráfico 5, é possível constatar que 35\% dos alunos avaliaram a estrutura da FES como muito insatisfatória, ou seja, consideraram-na deficitária e sem capacidade para suprir as necessidades básicas de ensino-aprendizagem, ao passo que, 27\% dos entrevistados classificaram a estrutura como insatisfatória, salientando o descontentamento dos estudantes em relação às condições físicas oferecidas pela faculdade. Desta forma, somando-se os percentuais dos níveis muito insatisfatório e insatisfatório, obteve-se um total de $62 \%$ de desagrado em relação ao ambiente da faculdade, o que denota a necessidade de melhorias prementes no mesmo.

A partir dos resultados apontados pela AFE, os principais atributos que contribuíram para a percepção da satisfação dos alunos quanto à infraestrutura da FES são os seguintes: estrutura física favorece o processo de ensino-aprendizagem (V12); biblioteca (V15) e iluminação (V17). Em contrapartida, os atributos que mais influenciaram para avaliação deficitária da infraestrutura da FES por parte dos alunos são: banheiro, estacionamento e iluminação.

Ademais, ressalta-se a aceitabilidade dos estudantes em relação à qualidade do ensino oferecido na FES/UFAM, isto é, relação entre professores e alunos, grade curricular, professores esclarecem dúvidas, entre outros atributos, pode ser considerada como satisfatória, uma vez que somando os percentuais dos níveis satisfatório e muito satisfatório do Gráfico 4 totalizou-se 43\%. Todavia, no estudo realizado por Rowe (2004) constatou-se descontentamento dos alunos com relação ao trabalho desenvolvido pelos professores em sala de aula. Assim, ao passo que os resultados obtidos na UFAM apontaram a estrutura física como objeto de descontentamento, na faculdade de Minas Gerais teve-se a qualidade do corpo docente como motivo do desagrado.

Desta forma, evidencia-se a relevância da realização de pesquisas de satisfação como mecanismo de melhoria contínua, tendo em vista que cada IES apresenta especificidades próprias, as quais demandam averiguações para efeito de um melhor entendimento de sua realidade e identificação de oportunidades de melhorias.

Com base nos dados do Gráfico 6, pôde-se concluir que os alunos dos cursos de Administração, Ciências Contábeis e Ciências Econômicas, esperam que seja melhorado, preferencialmente, na estrutura da FES os seguinte aspectos: instalações sanitárias com 36\% das citações; biblioteca com $20 \%$; e as salas de aula com $18 \%$. 


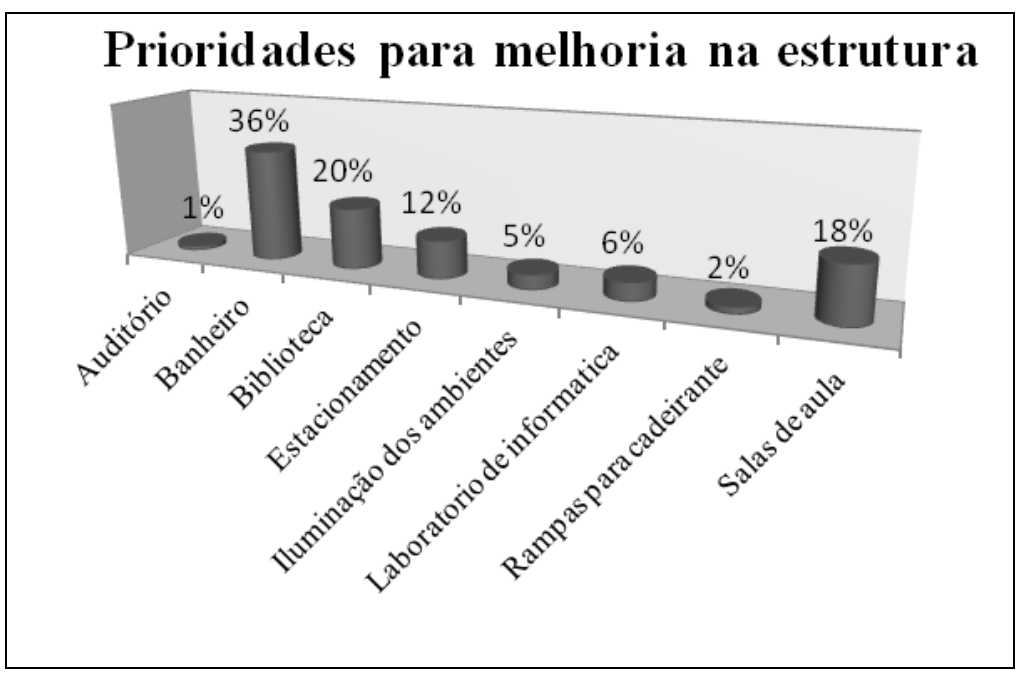

Gráfico 6 Prioridades para melhoria na estrutura Fonte: Pesquisa de campo (2011).

\section{CONCLUSÃO}

O presente estudo foi desenvolvido com o propósito de obter a análise de satisfação dos alunos da FES em relação às condições físico-pedagógicas oferecidas na faculdade. Para tanto, realizou-se uma pesquisa de campo, mediante a aplicação de um questionário formulado com base em três princípios: infraestrutura, ensino e aprendizagem.

Especificamente, esta pesquisa pretendeu identificar os motivos dos alunos para a escolha do curso e da universidade; analisar a opinião dos alunos em relação à infraestrutura geral da faculdade; examinar a opinião dos alunos com relação à qualidade do ensino, identificando a adequação do conteúdo curricular, práticas didáticas dos professores e correspondência entre as disciplinas e as demandas do mercado de trabalho.

Após a aferição dos dados pôde-se concluir que, o motivo pelo qual os alunos escolheram sua respectiva área foi, com 33\%, oportunidades que o curso oferece; enquanto $35 \%$ optaram pela Universidade Federal do Amazonas devido à qualidade do ensino.

Com a aplicação da Análise Fatorial Exploratória identificou-se que as variáveis procedimentos didáticos dos professores (V1), instrumentos adotados para desencadear a aprendizagem (V6) e mecanismos de avaliação de aprendizagem (V7), do grupo de características humanas, e estrutura física favorece o processo de ensino-aprendizagem (V12), biblioteca (V15) e iluminação (V17), do grupo de características físicas, foram as mais relevantes para avaliar o grau de satisfação dos alunos da FES.

No que concerne a satisfação dos alunos quanto à infraestrutura, 35\% avaliaram-na em aspectos gerais como muito insatisfatória; numa análise específica das dependências da 
faculdade, os atributos banheiros, biblioteca e salas de aula, foram considerados prioridades para melhoria. Em relação à qualidade de ensino, 35\% dos acadêmicos da FES classificaramna como regular, enquanto, $30 \%$ consideraram a qualidade do ensino satisfatória e $13 \%$ como muito satisfatória, em contrapartida, $17 \%$ a consideraram como insatisfatória e $5 \%$ muito insatisfatória. Logo, somando-se os níveis satisfatório e muito satisfatório, a qualidade do ensino totalizou um percentual de $43 \%$ de aceitação por parte dos alunos. Ainda em relação ao ensino, a assiduidade dos professores e o empenho dos docentes em articular atividades de ensino pesquisa e extensão constituíram as principais oportunidades de melhoria.

O objeto de estudo encontra-se em um estágio embrionário, isto é, com uma literatura ainda restrita. Todavia, acredita-se que esse estudo possa ser fator motivador para fomento de outras pesquisas, contribuindo para uma cultura de avaliação das instituições de ensino com a realização de projetos posteriores, bem como, para o progresso de outras ações, que possam subsidiar à tomada de decisões estratégicas das IES, aguçando as vantagens competitivas para essas instituições.

O estudo ainda colabora para que os alunos repensem acerca da educação, de forma a garantir um ensino de qualidade, capaz de suprir às suas expectativas e necessidades. Do mesmo modo que contribui, para que as instituições de ensino convirjam ao processo de acompanhamento da interação dos alunos com o mercado, e inspira a implantação de um novo modelo de gestão do ensino, no qual, o aluno é o elemento principal.

Conforme o exposto, torna-se evidente que para o estabelecimento de padrões de garantia da qualidade dos cursos ofertados, o processo de ensino-aprendizagem e o processo de gestão das IES, devem compreender a satisfação dos alunos envolvidos. O anseio de conhecer esta realidade nas IES impulsionou a realização do estudo que, por sua vez, proporcionou a seguinte indagação para investigações subsequentes: como a qualidade de ensino na FES classifica-se satisfatória, se não há uma infraestrutura adequada ao seu desenvolvimento?

\section{REFERÊNCIAS}

ANSARAH, M. R. Panorama do ensino em turismo no Brasil. Graduação e Pós-Graduação. Turismo em análise. São Paulo: Pioneira, 1996.

BERGER, R. L. F. Educação profissional no Brasil: novos rumos. Revista Íbero Americana de Educação, n. 20, p. 87-105, maio/ago. 1999. 
BRASIL. Ministério da Educação. Instrumento de Avaliação para o Reconhecimento dos Cursos de Graduação, Bacharelados e Licenciaturas. Brasília: MEC, janeiro de 2009.

CAMARGOS, M. A.; CAMARGOS, M. C. S.; MACHADO, C. J. Análise das preferências de ensino de alunos de um curso superior de Administração de Minas Gerais. Revista de Gestão USP, São Paulo, v. 13, n. 2, p. 1-14, abr./jun. 2006.

CAMPOS, D. F.; MARTINS, L. D. S.; LOPES NETO, M. Qualidade dos serviços na educação superior: uma visão comparativa entre dois cursos de graduação. In: SIMPÓSIO DE ADMINISTRAÇÃO DA PRODUÇÃO, LOGÍSTICA E OPERAÇÕES INTERNACIONAIS, XIV, São Paulo, 2011. Anais Online. São Paulo: SIMPOI, 2011. 16 p.

CORRAR, L. J.; PAULO, E.; DIAS FILHO, J. M. (coordenadores). Análise multivariada: para os cursos de administração, ciências contábeis e economia. 4. ed. São Paulo: Atlas, 2012.

DEMO, P. Desafios modernos da educação. Petrópolis: Vozes, 1998. DENCKER, A. F. M. Pesquisa e interdisciplinaridade no ensino superior: uma experiência no curso de turismo. São Paulo: Aleph, 2002.

MARTINS, P. L. A didática na atual organização do trabalho na escola: uma experiência metodológica. 1985. 214 f. Dissertação de Mestrado - Faculdade de Educação (FAE), Universidade Federal de Minas Gerais, Belo Horizonte.

NEVES, A. B.; RAMOS, C. F. A imagem das instituições de ensino superior e qualidade do ensino de graduação: a percepção dos acadêmicos do curso de administração. In: ENCONTRO NACIONAL DOS CURSOS DE GRADUAÇÃO EM ADMINISTRAÇÃO, 12, São Paulo, 2001. São Paulo: ENANGRAD, 2001. CD-ROM.

ROLIM, R. C., et al. Satisfação com o curso de graduação: um estudo junto aos estudantes de Administração da Universidade Federal de Lavras. In: ENCONTRO DA ANPAD, XXXI, Rio de Janeiro, 2007. Rio de Janeiro: EnANPAD, 2007. 14 p. CD-ROM.

ROWE, D. E. O. Perspectivas do ensino-aprendizagem e habilidades necessárias ao administrador: um estudo de caso. Revista Angrad, Rio de Janeiro, v. 5, n. 1, 41-61, jan./fev./mar. 2004.

SIQUEIRA, R. P.; CARVALHO, J. L. F. Qualidade do serviço educacional prestado por escolas de Administração: confronto entre uma universidade pública e uma faculdade privada. In: ENCONTRO DA ANPAD, XXX, Salvador, 2006. Salvador: EnANPAD, 2006. 16 p. CDROM.

UNIVERSIDADE FEDERAL DO AMAZONAS. Comissão Permanente de Avaliação. Retrospectiva da Avaliação da UFAM. Disponível em: $<\underline{\text { http://www.cpa.ufam.edu.br/projeto- }}$ de-avaliacao/12-retrospectiva-da-avaliacao-da-ufam.html>. Acesso em: 13 jun. 2011.

. Comissão Permanente de Avaliação. Justificativa. Disponível em:

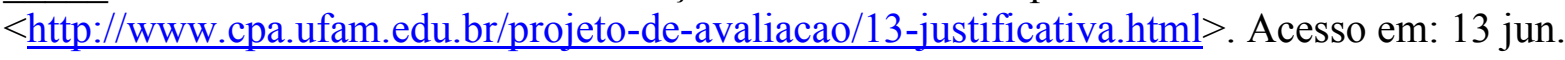
2011. 
Pró-Reitoria de Ensino de Graduação. Divisão de Matrícula. Dados referentes ao número de alunos matriculados na Faculdade de Estudos Sociais no primeiro semestre de 2011. Comunicação pessoal. Datada de: 6 jun. 2011.

Instituto de Ciências Exatas e da Terra. Departamento de Estatística. Cálculo Amostral. Comunicação pessoal. Datada de: 7 jun. 2011.

VANDERLEY, L. G.; KOTTWITZ, A. A percepção do aluno de Administração em relação à si próprio, aos discentes, aos docentes e ao seu curso. In: CONGRESSO VIRTUAL BRASILEIRO DE ADMINISTRAÇÃO, VIII, 2011. Anais online. CONVIBRA, 2011. 13 p.

VERGARA, S. C. Projetos e Relatórios de Pesquisa em Administração. 11. ed. São Paulo: Atlas, 2009.

VIEIRA, K. M.; MILACH, F. T.; HUPPES, D. Equações estruturais aplicadas à satisfação dos alunos: um estudo no curso de Ciências Contábeis da Universidade Federal de Santa Maria. Revista Contabilidade \& Finanças, São Paulo, v. 19, n. 48, 65-76, set./dez. 2008.

WALTER, S. A.; TONTINI, G.; DOMINGUES, M. J. C. S. Identificando oportunidades de melhoria em um curso superior através da análise da satisfação dos alunos. In: ENCONTRO DA ANPAD, XXIX, Brasília, 2005. Brasília: EnANPAD, 2005. 13 p. CD-ROM. 